\title{
Perhitungan Iuran Normal Program Pensiun dengan Asumsi Suku Bunga Mengikuti Model Vasicek
}

\author{
I Nyoman Widana \\ Program Study Matematika, Fakultas MIPA Universitas Udayana \\ e-mail: nwidana@yahoo.com \\ Ni Made Asih \\ Program Study Matematika, Fakultas MIPA Universitas Udayana \\ e-mail: madeasih@unud.ac.id
}

\begin{abstract}
Labor has a very important role for national development. One way to optimize their productivity is to guarantee a certainty to earn income after retirement. Therefore the government and the private sector must have a program that can ensure the sustainability of this financial support. One option is a pension plan. The purpose of this study is to calculate the normal cost with the interest rate assumed to follow the Vasicek model and analyze the normal contribution of the pension program participants. Vasicek model is used to match with the actual conditions. The method used in this research is the Projected Unit Credit Method and the Entry Age Normal method. The data source of this research is lecturers of FMIPA Unud. In addition, secondary data is also used in the form of the interest rate of Bank Indonesia for the period of January 2006-December 2015. The results of this study indicate that the older the age of the participants, when starting the pension program, the greater the first year normal cost and the smaller the benefit which he or she will get. Then, normal cost with constant interest rate greater than normal cost with Vasicek interest rate. This occurs because the Vasicek model predicts interest between $4.8879 \%$, up to $6.8384 \%$. While constant interest is only $4.25 \%$. In addition, using normal cost that proportional to salary, it is found that the older the age of the participants the greater the proportion of the salary for normal cost.
\end{abstract}

Keywords: Entry Age Normal, Normal Cost, Projected Unit Credit, Vasicek.

\section{Pendahuluan}

Tenaga kerja mempunyai peranan yang sangat penting bagi pembangunan nasional. Kemajuan atau kemunduran suatu negara dipengaruhi oleh produktivitas tenaga kerjanya. Salah satu cara untuk mengoptimalkan produktivitasnya adalah dengan menjamin kepastian untuk memperoleh penghasilan setelah masa pensiun. Hal ini akan memberikan rasa aman bagi tenaga kerja tersebut. Oleh karena itu pemerintah dan sektor swasta harus memiliki program yang dapat menjamin keberlangsungan dukungan finansial ini. Salah satu pilihannya adalah program pensiun. Adam [1] 
dalam penelitiannya menghitung besar iuran normal dengan metode Entry Age Normal dengan menggunakan asumsi tingkat suku bunga konstan sebesar 7 \% Sedangkan [6] membahas tentang perhitungan aktuaria untuk manfaat pensiun- normal menggunakan metode Projected Unit Credit (PUC) dan Entry Age Normal (EAN) dengan asumsi tingkat suku bunga sebesar $10 \%$. Peneliti lainnya, [7] menggunakan metode Projected Unit Credit dan Entry Age Normal dalam pembiayaan pensiun. Ketiga penelitian tersebut menggunakan asumsi tingkat suku bunga konstan. Tetapi, pada kondisi riilnya besar tingkat suku bunganya tidak selalu sama. Disisi lain, [5] telah menghitung nilai anuitas dengan tingkat bunga berubah secara stokastik. Oleh karena itu, penelitian ini akan menghitung iuran normal dengan menggunakan asumsi tingkat suku bunga yang tidak konstan. Sedangkan tujuan dari penelitian ini adalah:Menghitung besarnya iuran normal program pensiun yang ditetapkan dengan metode $P U C$ dan metode EAN dengan asumsi tingkat suku bunga mengikuti model Vasicek dan menganalisis iuran normal dari para pesarta program pensiun.

\section{Metode Penelitian}

Sumber data penelitian ini adalah tenaga pendidik FMIPA Unud. Kemudian Data ini diklasifikasikan berdasarkan umur dan gaji pokok pada saat ini. Selain itu digunakan juga data sekunder berupa rata-rata tingkat suku bunga bulanan Bank Indonesia periode Januari 2006 - Desember 2015 . Sedangkan pengolahan datanya menggunakan Program $R$ dan Microsoft Excell .

Peluang seorang yang berusia $x$ tahun akan mencapai usia $x+t$ tahun dinotasikan dengan ${ }_{t} p_{x}=P\left[T_{x}>t\right]$, dengan $T_{x}$ varibel random yang menyatakan sisa usia dari orang yang berusai $x$ tahun [4]. Dari [3] diketahui bahwa

$$
\ddot{a}_{x}=E[Y]=\sum_{k=0}^{\infty} v_{k}^{k} p_{x}
$$

Selanjutnya, Vasicek mengemukakan suatu model model persamaan diferensial untuk menggambarkan tingkat suku bunga yang bergerak secara fluktuatif. Adapun persamaan diferensialnya adalah sebagai berikut [5]

$$
d r(t)=k(\theta-r(t)) d t+\sigma d W(t)
$$

dengan $r(t)$ menyatakan tingkat suku bunga pada saat $t$. Koefisien $k$ menyatakan laju penyesuaian tingkat suku bunga menuju tingkat suku bunga jangka panjang. $\theta$ adalah tingkat suku bunga jangka panjang dan $\sigma$ adalah volatilitas. $W(t)$ adalah gerak Brown atau proses Wiener pada waktu $t$.

Ekspektasi nilai tunai pembayaran sebesar satu unit pada saat $t$ dengan tingkat suku bunga mengikuti model Vasicek dinotasikan dengan $P(t)$ [5] dan didefinisikan sebagai 


$$
P(t)=\exp \left\{\left(\theta-\frac{\sigma^{2}}{2 \kappa^{2}}\right)(B(t)-t)-\frac{\sigma^{2}}{4 \kappa} B(t)^{2}-r(0) B(t)\right\}
$$

dengan $B(t)=\frac{1-e^{-\kappa t}}{\kappa}$

Iuran Normal atau normal cost $(N C)$ adalah iuran tahunan yang dibayarkan pada tiap tahun masa kerja peserta aktif. Pada prinsipnya iuran normal digunakan untuk mencicil nilai tunai dari future benefit (FVFB) masing-masing peserta [6]. Misalkan $B_{r}$ adalah besar manfaat pensiun dan $r$ usia pensiun maka nilai sekarang dari manfaat pensiun untuk orang yang berusia $x$ tahun adalah

$$
{ }^{r}(P V F B)_{x}=B_{r} \ddot{a}_{r} v_{r-x}^{r-x} p_{x}
$$

Prinsip dasar untuk menentukan besar iuran normal [7] adalah sebagai berikut

$$
{ }^{r}(P V F B)_{e}={ }^{r}(\text { PVFNC })_{e}
$$

Ada dua metode untuk menentukan besar iuran normal,dengan bunga konstan [5], yaitu

$$
\begin{gathered}
E A N{ }^{r}(N C)_{e}=\frac{v^{x-e}{ }_{x-e} p_{e}}{\ddot{a}_{e: \bar{r}-e \mid}}{ }^{r}(P V F B)_{x} \\
\operatorname{PUC~} r^{r}(N C)_{x}=\frac{r_{(P V F B)_{x}}}{r-e}
\end{gathered}
$$

\section{Hasil dan Pembahasan}

Penaksiran parameter suku bunga model Vasicek dilakukan berdasarkan data rata-rata tingkat suku bunga bulanan Bank Indonesia, Gambar 1.



Gambar 1. Rata-Rata Tingkat Suku Bunga Bulanan BI

Adapun hasilnya adalah sebagai berikut: $\kappa=0,5202675, \theta=0,0662197$, dan $\sigma=$ 0,00628030 . Selanjutnya hasil estimasi parameter ini dimanfaatkan untuk mementukan ekspektasi dari nilai tunai pembayaran sebesar 1 unit yang dilakukan pada saat $t$ tahun 
dari sekarang dengan menggunakan (1) dan mengambil $r(0)=4,25 \%$, hal ini sesuai dengan tingkat suku bunga saat ini.

Selanjutnya akan dibahas manfaat peniun. Data peserta program pensiun, dalam hal ini adalah tenaga pendidik dari FMIPA Unud, kecuali Guru Besar, memuat umur beserta gaji pokoknya. Dari data yang diperoleh terlihat bahwa usia dari tenaga pendidik yang berjumlah 167 orang,berkisar antara usia 28 tahun sampai dengan 64 tahun. Sedangkan besarnya gaji pokoknya berada di rentang 2,781,100 - 5,173,400. Selanjutnya diasumsikan peserta mengikuti program pensiun mulai tahun 2017, usia pensiunnya adalah 65 tahun. Besar benefit pensiun yang akan diterima adalah $70 \%$, ideal replacement rate, dari proyeksi gaji satu tahun sebelum memasuki usia pensiun. Perhitungan besar gajinya, dihitung dengan asumsi kenaikan gajinya sebesar 4\% per tahun. Asumsi ini diambil mengingat rata-rata tingkat inflasi nasional adalah sebesar $3,91 \%$. Berdasarkan hal ini, besar manfaat pensiun yang akan diterima oleh peserta saat mulai memasuki usia pensiun berkisar anatara 37.123.632,00 sampai dengan 93.918.332,34 rupiah per tahun. Variasi benefit ini dipengaruhi oleh usia dan gaji pokok dari peserta. Sedangkan mean (rata-rata) benefitnya adalah 62.639.971,82 rupiah.

Agar memperoleh benefit yang telah dibahas pada bagian sebelumnya, peserta program pensiun harus membayarkan sejumlah uang, disebut Iuran normal (normal cost). Besar iuran normal yang dihitung dengan menggunakan Metode Entry Age Normal dan Projected Unit Credit, dengan tingkat bunga yang bunga yang diasumsikan mengikuti model Vasicek, berturut-turut adalah sebagai berikut:

$$
\begin{aligned}
& \text { EAN } r(N C)_{e}=B_{r} \frac{\sum_{t=r}^{\infty} P(t){ }_{t} p_{e}}{\sum_{t=0}^{r-1} P(t){ }_{t} p_{e}} \\
& \text { PUC }{ }^{r}(N C)_{x}=\frac{=B_{r} \sum_{t=r}^{\infty} P(t) l_{t}}{(r-e) P(x) l_{x}}
\end{aligned}
$$

Pembuktiannya dapat dilakukan dengan menggunakan (2), (3), dan prinsip ekuivalensi.

Hasil perhitungan dari benefit dan normal cost (NC) dengan menggunakan (4) diperlihatkan oleh Gambar 2 


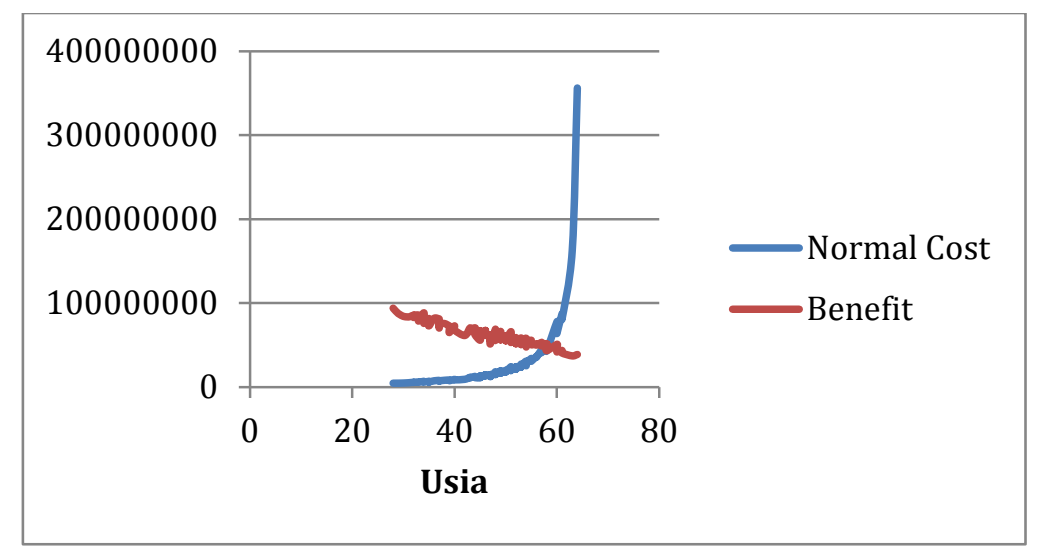

Gambar 2. Hubungan Antara Usia dengan NC dan Benefit

Gambar 2 memperlihatkan bahwa semakin tua usia dari peserta, ketika mulai mengikuti program pensiun, maka semakin besar normal cost tahun pertamanya dan semakin kecil benefit yang akan diperolehnya. Agar lebih jelas, hasil perhitungan normal cost dan benefit per tahun dari beberapa peserta dengan menggunakan (4) dan (5) dapat dilihat pada Tabel 1.

Tabel 1. Benefit dan Normal Cost

\begin{tabular}{|c|l|c|c|}
\hline Usia & Benefit & $E A N r(N C)_{e}$ & $\operatorname{PUC} r(N C)_{x}$ \\
\hline 28 & $93.918 .332,34$ & $4.595 .302,56$ & $\begin{array}{c}1.797 .458- \\
22.413 .489\end{array}$ \\
\hline 30 & $84.181 .005,88$ & $4.783 .930,11$ & $\begin{array}{c}1.947 .330- \\
21.237 .851\end{array}$ \\
\hline 32 & $82.810 .112,20$ & $5.479 .786,74$ & $\begin{array}{c}2.323 .696- \\
22.158 .208\end{array}$ \\
\hline
\end{tabular}

Selanjutnya, Gambar 3 menampilkan normal cost dengan bunga konstan dan dengan bunga vasicek



Gambar 3. Normal Cost Bunga Konstan dan Vasicek 
Gambar 3. memperlihatkan bahwa normal cost dengan bunga konstan lebih besar daripada normal cost dengan bunga Vasicek.

Sekarang akan dibahas normal cost yang besarnya sebanding dengan gaji pokok. Khususnya, kenaikan gajinya sama dengan diskonnya. Untuk Kasus ini, normal cost untuk bunga Vasicek adalah

$$
\begin{gathered}
E A N{ }^{r}(N C)_{e}=K * \text { Gaji Pokok sat ini } \\
K=0,7 *(1,04)^{64-x} \frac{\sum_{t=r}^{\infty} P(t){ }_{t} p_{e}}{\sum_{t=0}^{r-1} p_{e}}
\end{gathered}
$$

Dengan menggunakan (6) dan (7), diperoleh bahwa peserta dengan usia 28 tahun proporsi gajinya untuk iuran normal adalah sebesar 5,78857\% dari gaji pokoknya . Sedangkan untuk peserta dengan usia 34 tahun proposinya 8,20054\% dari gaji pokonya. Lebih lanjut, untuk peserta dengan usia dari 28 - 64 tahun diperoleh bahwa semakin tua usia peserta saat mulai menjadi peserta maka akan semakin besar proporsi gajinya untuk iuran normal cost.

\section{Kesimpulan dan Saran}

Hasil peneltian ini menunjukkan semakin tua usia dari peserta, ketika mulai mengikuti program pensiun, maka semakin besar normal cost tahun pertamanya dan semakin kecil benefit yang akan diperolehnya. Kemudian, normal cost dengan bunga konstan lebih besar daripada normal cost dengan bunga Vasicek. Selain itu, untuk normal cost yang proportional dengan gaji, diperoleh bahwa semakin tua usia dari peserta maka akan semakin besar proporsi gajinya untuk normal cost. Peserta dengan usia 28 tahun proporsi gajinya untuk iuran normal tahun pertama adalah sebesar 5,78857\%( Rp 1.892.445,61) dengan benefit sebesar Rp. 93.918.332,34 per tahun.

Pada penelitian ini digunakan model Vasicek. Untuk penelitian selanjutnya disarankan menggunakan model Cox-Ingersol-Ross (CIR).

\section{Daftar Pustaka}

[1] F.F Adam., "Perhitungan Biaya Normal Program Pensiun Usia Normal dengan Metode Entry Age Normal (Percent Dollar", Jurnal Vokasi Indonesia Volume 2 No. 1, 2014.

[2] W.H J Aitken, A Problem-Solving Approach to Pension Funding and Valuation. Ed ke-2. Winsted: ACTEX Publications,1994

[3] N.L.Bowers, H.U. Gerber., J.C. Hickman, D.A. Jones, dan C.J. Nesbitt, Actuarial Mathematics. Schaumburg (DE): The Society of Actuaries, 1997. 
[4] D.C.M Dickson, M.R Hardy, dan H.R Waters, Actuarial Mathematics for Life Contingent Risks. Cambridge: Cambridge University Press, 2009

[5] D.S. Kumala, J.Ferr., K.Farah., "Perhitungan Nilai-Nilai Aktuaria dengan Asumsi Tingkat Suku Bunga berubah Secara Stokastik". Jurnal Mat. Stat Vol. 11, 2011

[6] Oktiani I. "Perhitungan Aktuaria untuk Manfaat Pensiun-Normal Menggunakan Metode Projected Unit Credit dan Entry Age Normal" [skripsi] Institut Pertanian Bogor., 2013

[7] Utami A.H.B., Wilandari Y., Wuryandari T., "Penggunaan Metode Projected Unit Credit dan Entry Age Normal Dalam Pembiayaan Pensiun. " Jurnal Gaussian Vol. 1 Nomor 1,2012 